dome. On the horizon indeed these indications cease to serve us; there the clouds, like the mountains, appear to be evenly painted on a vertical or nearly vertical background, which gradually passes into the surface of the earth below, and into the firmament above. Now, since the senses supply no criteria by which we distinguish between the distance of the clouds and that of the sky, it seems only natural that we should ascribe to the one the ascertained form of the other, so far, at least, as we can separate them. This, I believe, is the way in which our conception of the sky, as a flat domelike vault, must originate, vague, variable, indefinite as that conception undoubtedly is.

"Moreover, the apparent increase in the size of the sun or the moon is never very striking or decided, except at those times when the air near the horizon is heavily charged with vapour, and when, as a necessary consequence, the heavenly bodies in question only shine with a very feeble light; we have then the very same effect with which we are perfectly familiar in the case of distant mountains. They appear more distant than they do when the air is clear, and therefore larger. Moreover, when suitable terrestrial objects happen to be placed near the horizon, they add very much to the effect. When, for instance, the moon sets near a tree some twenty feet in diameter, and about 1,000 yards off, as she subtends the same visual angle, and is known to be far more distant, she appears to be very much larger; whereas, when the moon sets behind a flat horizon, there is no object of comparison to enable us to perceive that her small apparent may represent a very great absolute magnitude.

"When I look at the moon reflected from a piece of parallel glass, so that her image appears to be very near the horizon, I do not find that the image looks decidedly larger than the moon herself seen directly high in the sky, although in this way it is easy to compare the apparent magnitude of the reflected imagre with that of the terrestrial objects seen together with it. In this case it is evident the refle ted image has not the effect of being seen through the vaporous portion of the atmosphere.

"To my eye, the apparent increase in magnitude near the horizon is much more apparent in the case of the moon than in that of the sun. When the form of the sun can be distinguished at all, his light is generally s, dazzling that we camnot louk at him steadily, and consequently cannot compare him directly with any terrestrial objects that happen to be on the herizon. Even in the case of the morn when the sky is quite clear, the delusion is not so apparent. In all cases the delusion depends in a very great degree on the state of the atmosphere."

\section{Occurrence of the Little Egret}

AN adult specimen of the Little Egret (Ardea garzetta, Linn.) was shot at the end of last month, on the mud-flats below Topsham, a town on the Exe, four miles below Exeter, and has unfortunately fallen into private hands. This is the first known occurrence of this beautiful burd on the Exe, but two or three specimens were recorded from the Dart and Tamar more than fifty years ago. The last specimen obtained in South Devon was killed in April $185 \mathrm{I}$.

A nearly adult male Montagu's Harrier was shot near Christon, Devon, last month, and I have obtained it for the collection in this Institution. The female bird has since been seen.

\section{W. S. M. D'URBAN}

Devon and Exeter Albert Memorial Museum, Queen Street, Exeter, June 13

\section{Pinkish Colour of the Sun}

IN addition to the several accounts of the curious pinkish appearance of the sun, noticed in the numbers for May 26 and June 2 of your journal, it may perhaps interest your correspondents and the readers of NATURE to know that the sun presented a round disc of a very unusual pinkish colour, here and at Cranbrook (about five miles north-east from Hawkhurst), in Kent, between five and six o'clock P.M. on the afternoon of Monday, the 23 rd ult. It was so seen by muself at Cranbrook, in company with several others, who thought that the colour was quite unusual, shining througl a thick haze of apparently low cirrostratus, but which was perhaps rain cloud, as the air at the time was light from the north, and cold, while the mist, or haze, seemed to be at no very great elevation above the ground, and considerably lower than these ordinary forms of cirrostratus in which halos and mock-suns are generally seen.

The colour observed here was a pinkish buff, or such a mixture of pink and yellow as to suggest the abundance of more blue and violet, and the absence of more yellow light than in the orange and reddish tints, generally seen in the setting sun, so as to resemble the colour of very pale blotting-paper, or a light flesh-colour. While the disc was still clearly seen of this colour, two or three sun-spots were visible upon it with the naked eye. These could no longer be distinguished at six o'clock, when the peculiar pinkish hue was also succeeded by the ordinary yellow of the sun's disc near the horizon, seen through a thick haze. On the same afternoon (of the $23 \mathrm{rd}$ ) the appearance of the sun's round disc through a thick cloud of haze in the sky was noticed, for a considerable time, as visible with rare and unusual distinctness at Tunbridge Wells, in Kent.

\section{Collingwood, Hawkhurst, June 8}

\section{A. S. Herschel,}

\section{La Petite Culture en Belgique}

I ENCLOSE drawings of earthern pots, which I observed nailed against the south side of a farm-house near this. These pots are for sparrows' nests, and the young, when fledged, are taken
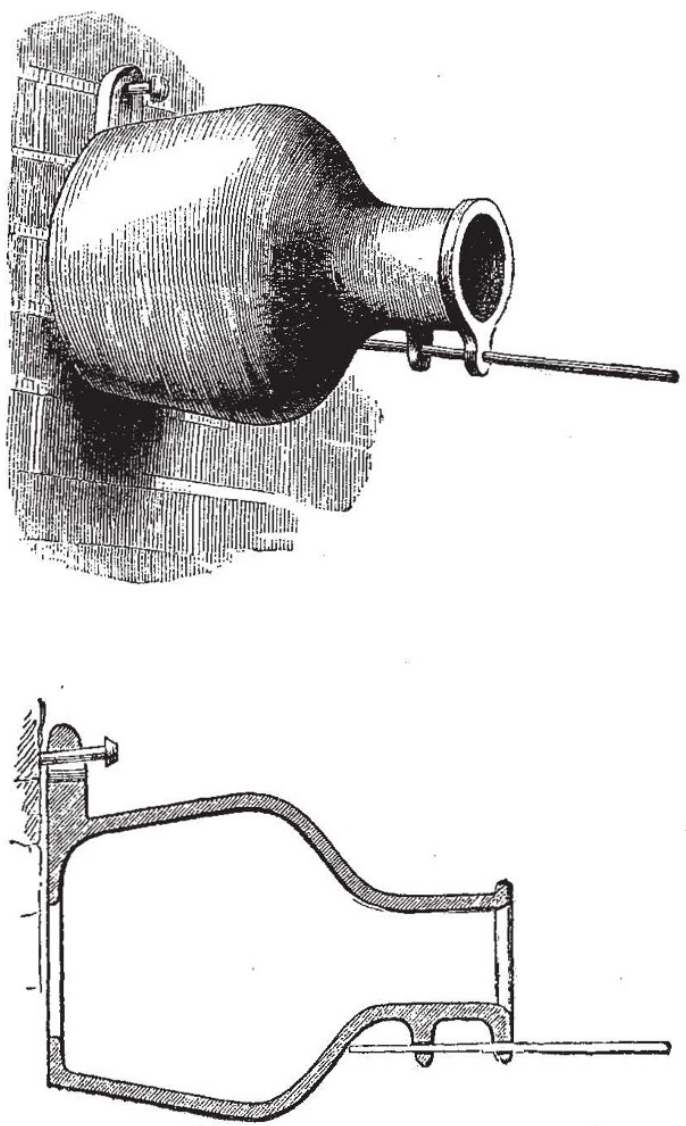

and eaten. I think this form of "La petite culture" cannot be commended in a country so swarming with insects as Belgium, and I inter from the careful make of the pots that the custom is not a new one, though it may be new to some of the readers of NATURE. Louvain, June 4
N. A. Straples 